\title{
The Influence of Students' Perceptions on Mathematics Performance. A Case of a Selected High School in South Africa
}

\author{
Paul Mutodi \\ Department of Maths, Science and Technology, University of Limpopo (Turfloop Campus) \\ E-mail:paul.mutodi@ul.ac.za \\ Hlanganipai Ngirande \\ Department of Business Management, University of Limpopo (Turfloop Campus) \\ E-mail: hlanganipai.ngirande@ul.ac.za
}

Doi:10.5901/mjss.2014.v5n3p431

\section{Abstract}

This study investigates the influence of students' perceptions on mathematics performance at a selected South African secondary school. The influence of factors such as strength and weaknesses in mathematics, teacher support/learning material, family background and support, interest in mathematics, difficulties or challenges in doing mathematics, selfconfidence and myths and beliefs about mathematics were identified as constructs of perceptions that influence students' performance. Five of the seven constructs were found to be influential on students' performance in mathematics. Quantitative methods were used to analyse the data collected from a questionnaire which was administered to randomly selected secondary school students $(n=124)$ in Polokwane, South Africa. From the regression analysis of the data, the following hierarchy of themes emerged as components of students' perceptions of mathematics. These were (i) weaknesses in mathematics (ii) family background and support, (iii) interests in mathematics, (iv) self-confidence in mathematics, (v) myths and beliefs about mathematics (vi) teacher /learning material support, (vii) difficulties in learning mathematics. Results from $t$ tests, Anova and suggest that there were significant differences in the perceptions and beliefs about mathematics between males and females, between mature and juvenile students and among students from different language backgrounds respectively. Correlation analysis results showed strong positive relationships between performance and perception constructs such as self-confidence, interests in mathematics, teacher and learning support material as well as myths and beliefs. The respondents tend to view lack of proficiency in mathematics as a challenge, and attribute success in mathematics to effort and perseverance. Students also perceive difficulty in mathematics as an obstacle, and attribute failure to their own lack of inherited mathematical ability. These findings suggest that differences in (i) myths and beliefs about mathematics success, ( (ii) motivation given by mathematics teachers and parents, (iii) mathematics teachers' teaching styles and learning materials and (iv) self confidence in mathematics may lead to differences in perceptions about mathematics. These in turn may lead to differences in attitudes towards mathematics and learning mathematics which have a bearing on performance.

Keywords: Perceptions, Mathematics Achievement, Attitudes, Beliefs, secondary school students

\section{Introduction}

This study explores the influence of students' perceptions on mathematics achievement at a selected secondary school in Polokwane, South Africa. Seven perceptual variables which influence students' achievement were identified. Mathematical perceptions considered for this study include individual constructs that are generated by individual experiences (student characteristics), home and societal context of the student and those emanating from classroom experiences (Hannula, 2007). Studies generally have found boys to hold a more positive attitude towards mathematics (e.g. Kaasila, Hannula, Laine \& Pehkonen, 2006). In this study, the term 'perceptions of mathematics' is conceptualised as a mental representation or view of mathematics, apparently constructed as a result of social experiences, mediated through interactions at school, or the influence of parents, teachers, peers or mass media. It also refers to some kind of mental representation of something, originated from past experience as well as associated beliefs, attitudes and conceptions. There are several studies that focus on investigating the perceptions that students have about mathematics itself (Picker \& Berry, 2000; Rensaa 2006; Aguilar, 2012; Moreau, Mendick \& Epstein, 2010). Despite this large body of research, there is a lack of research on views and beliefs held by South Africa secondary school students. 
In South Africa mathematics is a perceived as a difficult subject, accessible only to the few. Adults frequently claim dislike or incompetence towards the subject, while many students choose not to pursue mathematics post-compulsory education. Recent studies (e.g. Sterling, 2004, de Villiers, 2010) indicate that there is a critical shortage of people qualified in mathematics in South Africa. Mathematics achievement in South Africa is abnormally poor (Spaull, 2012). In addition; there is the recent decline in recruitment into higher education courses in mathematics, science, technology and engineering noted in South Africa where negative views of mathematics (and science) are often cited as contributory factors(Fry,2006).Many theories have been advocated to explain the overall poor performance at all grade levels. Students who perform well in mathematics are treated as "nerds". Many people generally dislike mathematics. It is seen as a subject reserved for the selected few. It often evokes feelings of stress; anxiety and fear (Atallah, Bryant and Dada, 2009). Furthermore, it is seen as a filter that hinders students from pursuing their career aspirations mathematics and science -related fields (Fisher, 2008).

Perceptions and beliefs about mathematics originate from past experiences; comprising both cognitive and affective dimensions Aguilar, Rosas and Juan Zavaleta (2012). From a cognitive point of view it relates to a person's knowledge, beliefs, and other cognitive representations while from an affective domain it refers to a person's attitudes, feelings and emotions about mathematics. The term is also understood broadly to include all visual, verbal representations, metaphorical images and associations, beliefs, attitudes and feelings related to mathematics and mathematics learning experiences. Therefore, the main aim of this study is to explore and identify the range of perceptions, beliefs and attitudes towards mathematics as it is perceived by the secondary school students.

It is widely claimed that, negative perceptions and myths of mathematics are widespread among the students, especially in the developed countries (e.g., Mtetwa \& Garofalo, 1989; Ernest, 1996; \& Gadanidis, 2012). Sam (2002) claimed that many students are scared of mathematics and feel powerless in the presence of mathematical ideas. They regarded Mathematics as "difficult, cold, abstract, and in many cultures, largely masculine" (Ernest, 1996, p.802). Buxton, cited by Sam (2002) viewed mathematics as "fixed, immutable, external, intractable and uncreative" or "a timedtest"(p.115). Even scientists and engineers whose jobs are related to mathematics "often harbour an image of mathematics as a well-stocked warehouse from which to select ready-to-use formulae, theorems, and results to advance their own theories"(Peterson, 1996).

Educators attempt to explain this phenomenon through the widespread beliefs or mathematical myths that "learning mathematics is a question more of ability than effort"(McLeod, 1992, p.575) or "there is an inherent natural ability for mathematics"(Fitz Simons et al., 1996, p. 768). Many people hold the view that mathematics is only for the clever ones, or only for those who have 'inherited mathematical ability'. Another widely held belief is that mathematics is a male dominant subject. One other stereotyped image is that boys are better in mathematics than girls (Ernest, 2001). Thus, many adults accept this lack of accomplishment in mathematics as a permanent state over which they have little control. Parents and significance others have a strong influence on students' beliefs and attitudes towards mathematics (McLeod, 1989). Students' mathematics learning outcomes are strongly related to their beliefs and attitudes towards mathematics (Furinghetti \& Pehkonen, 2000; Leder, Pehkonen, \& Törner, 2002; Pehkonen, 2003). According Sam (2002) parents' views about mathematics have strong effect on the way they teach their children. This often creates tension between the parents and teachers if they share contrasting images of mathematics.

One origin of different student perceptions is the individual life histories that each student brings to mathematics learning. These life histories influence the way the students position themselves in the classroom, the way they engage with mathematics, teacher and peers and the way they interpret mathematical experiences. On the other hand, there are contextual factors that students of the same class share with each other. These are, for example, the personality of the teacher, quality of teaching and learning support material, interests in mathematics, self -confidence and general proficiency in the subject. These influence all students in a class and are the origin of shared experiences. Moreover, also students' individual experiences are partly shaped by the shared events in the classroom. This is illustrated with an arrow from classroom context to individual experiences.

\section{Objectives of the Study}

The objectives of this study are:

1. To identify the range of student's perceptions towards mathematics held by South African students.

2. To examine whether there is a relationship between the identified perception constructs and student performance in mathematics.

3. To examine whether gender, age and language background have an effect on the way students perceive 
mathematics and how these perceptions influence performance.

4. To give recommendations to authorities on strategies that can be employed to enhance positive perceptions towards mathematics.

\section{Research Questions of the Study}

The research question that guides this study is:

1. Which of the identified perception constructs have a direct influence on students' performance?

\section{Research Hypotheses}

$\mathrm{H}_{1}$ : There is a significant relationship between students' perceptions and mathematics performance.

$\mathrm{H}_{2}$ : There is a significant difference between the perceptions of male and female students towards mathematics performance

\section{Significance of the Study}

By examining the different images, attitudes, belief and myths of mathematics that students hold, there is a potential for such images, attitudes, beliefs to be challenged, promoted or discouraged. The information obtained will enhance better strategies and measures for promoting student understanding and participation in mathematics related fields. The results of this study might inform the extent of the influences of parents and teachers in shaping students' perceptions of mathematics. This information can be used to promote positive influence while attempting to avoid the negative influences of these sources. It will help to understand better the roles of parents and teachers in the shaping of students' images of mathematics. The findings will reflect possible implication for mathematics education and mathematics teacher education. Knowing how students perceive mathematics learning experiences in school and how this could influence their images of mathematics will help us to understand better how mathematics should be presented in the classroom. This knowledge may also help to enhance better curriculum planning and teacher development programmes. Students' views of mathematics are important as they can shape the way in which they learn mathematics. Such views and perceptions may have more influence than knowledge in determining how individuals organise and define tasks. Perceptions of what mathematics is and is not, may affect attitudes, performance, confidence and perceived usefulness of mathematics.

\section{Literature Review and Theoretical Orientations}

To find a well-developed, well-defined theoretical framework in the study of beliefs and attitudes is a challenge and the endeavour to develop one coherent framework for this area has been unfruitful for many researchers. According to Hannula (2004) there are on-going debates on the theoretical frameworks used in the conceptualisation of affect in mathematics education. Currently there is no precise, shared language for describing the affective domain, within a theoretical framework that permits its systematic study. Thus, this study is guided by different notions and discusses the relationship between their conceptions. The constructs, beliefs and attitudes, images, views, perspectives and opinions are not directly observable and have to be inferred, and because of their closeness it is problematic to have a common definition of these notions (Leder \& Forgasz, 2002). Efforts by researchers to isolate these concepts yield no acceptable results. Kislenko, Grevholm, and Lepik (2005) explained the interplay among thinking, feeling, opinions, beliefs, views and perspectives. They argued that beliefs are a part of persons' knowledge that is highly subjective and on the other hand the conceptions feelings and beliefs are often overlapping and cannot be distinguished. Some researchers consider beliefs to be part of knowledge (e.g. Furinghetti, 2003; Renzi, 2005, Brown, 2006), some think beliefs are part of attitudes (e.g. Pehkonen and Pietilä, 2004), and some consider them as part of conceptions (e.g. Thompson, 1992).

Ignacio, Nieto and Barona (2006) used the term mathematics self-concept to refer to personal beliefs relating to the world of mathematics, what is to the set of ideas, judgements, beliefs, and attributions that the person has steadily built up during his or her process of learning in the school environment. Personal beliefs affect the person's interest in mathematics, efficiency in performing mathematics tasks, motivation and pleasure with mathematics, attribution of causes to academic success or failure, and self-concept as belonging to a certain social group. Hannula (2006) pointed out that a mathematics learner's liking or disliking of mathematics derives from his/her belief structure. People's beliefs 
and attitudes towards mathematics are shaped by individual personal characteristics and experiences related to their academic self-image. An individual's view of mathematics is a compound of knowledge, beliefs, conceptions, attitudes, and feelings. Literature suggests that attitudes and beliefs are interlinked. Kayander and Lovric (2005) claims that attitudes may influence the formation of new beliefs.

Beliefs might be thought of as lenses through which one looks when interpreting the world (Philipp, 2006). Research shows that the beliefs and feelings adults experienced as learners carry forward to their adult lives, and these feelings are important factors in the ways they relate to the new generation of learners. There is a lack of interest in mathematics or a relatively higher tendency of mathematics avoidance among many of the South African students. Most students hold the belief or myth that being good in mathematics is mainly due to ability than effort (McLeod, 1992). Many students admit this lack of achievement in mathematics as a permanent state over which they have little control. According to Tobias (2003), millions of adults are blocked from professional and personal opportunities because they fear or perform poorly in mathematics, for many these negative experiences remain throughout their lives.

Moscucci (2008) discussed 'a meta-belief systems activity' on the basis of learning experimentation, where the importance of making learners aware of their belief systems regarding mathematics became apparent. Many of a teacher's beliefs and views seem to originate in and be shaped by experiences" (Thompson, 1992, p. 139).Pajares asserts that whereas beliefs that are formed from experiences appear to be more resistant, "learning and inquiries are dependent on prior beliefs".

There is need for teachers to learn about their students from the students themselves. Pedagogy that is intended to improve students' academic achievement needs to be informed by the students themselves. Insight into the perceptions of the learners with regard to their mathematical experiences can prove beneficial in developing effective pedagogy for improved mathematics achievement. South African students, in particular, are in need of effective pedagogy that will improve their school mathematics performance. The purpose of this study is to provide insights into the perceptions of South African students with respect to their experiences inside and outside classrooms, with or without their teachers. Implications of these perceptions may inform pedagogical considerations in improving the mathematics achievement of South African tertiary students.

The conceptions, attitudes, and expectations of the students regarding mathematics and mathematics teaching have been considered to be very significant factor underlying their school experience and achievement (Borasi, 1990; Schoenfeld, 2008). These conceptions determine the way students approach mathematics tasks, in many cases leading them into non-productive paths. Students have been found to hold a strong procedural and rule- oriented view of mathematics and to assume that mathematical questions should be quickly solvable in just a few steps, the goal just being to get "right answers". For them, the role of the student is to receive mathematical knowledge and to be able to demonstrate so; the role of the teacher is to transmit this knowledge and to ascertain that students acquired it (Borasi, 1990). Such conceptions may prevent the students from understanding that there are alternative strategies and approaches to many mathematical problems, different ways of defining concepts, and even different constructions due to different starting points. They may approach the tasks in the mathematical class with a very narrow frame of mind that keeps them from developing personal methods and build confidence in dealing with mathematical ideas.

Crawford et al. (1993) found that the majority of students perceived mathematics as "numbers, rules and formulae" (p. 213). For some students awareness of mathematics involves simply the recall of facts and the use of formal procedures. These views were associated with what he calls a "surface approach" to learning mathematics, that is, "the reproduction of knowledge and procedures"( p. 212). Research revealed that many students relate mathematics mainly with computations (Iddo \& Ginsburg, 1994). Many students tend to identify mathematics with arithmetic. Doing mathematics is normally associated with calculations. It is widely maintained in the literature that negative images and myths of mathematics are widespread among the students. Many students view mathematics as a difficult, cold and abstract subject. It is perceived by many students as an exclusive discipline Buhagiar (2013). From epistemological and pedagogical perspectives, it is perceived as a subject that involves a lot of work. The subject is seen as an obstacle, often dreaded and as hard work. Mathematics is also viewed as a static and objective discipline, available for discovery by mathematicians, in turn to be transmitted by teachers and received by the students.

Many students seem to concentrate on computations as the essence of mathematics. Many believe that mathematical activity includes procedures that are divorced from real life, from discovery and from problem solving. The fact that mathematics is usually presented as a body of absolute truths which exists independently of the learners and taught in a hierarchical, linear and prescriptive fashion reinforces the view that mathematics is a difficult subject. There is also a claim that mathematics is only for the clever ones, or only for those who have inherited mathematical ability (Kimball \& Smith, 2013). Being mathematically knowledgeable is often treated as an indicator of general intelligence, as 
evidenced by the widespread use of mathematics in entrance tests. This view causes many people to believe that learning mathematics is a question of ability rather than effort and that there is an inherent natural ability for mathematics. This perception leads students to accept their lack of accomplishment in mathematics as a permanent state over which they have little control.

Figure 1: Mathematical Perceptions development model

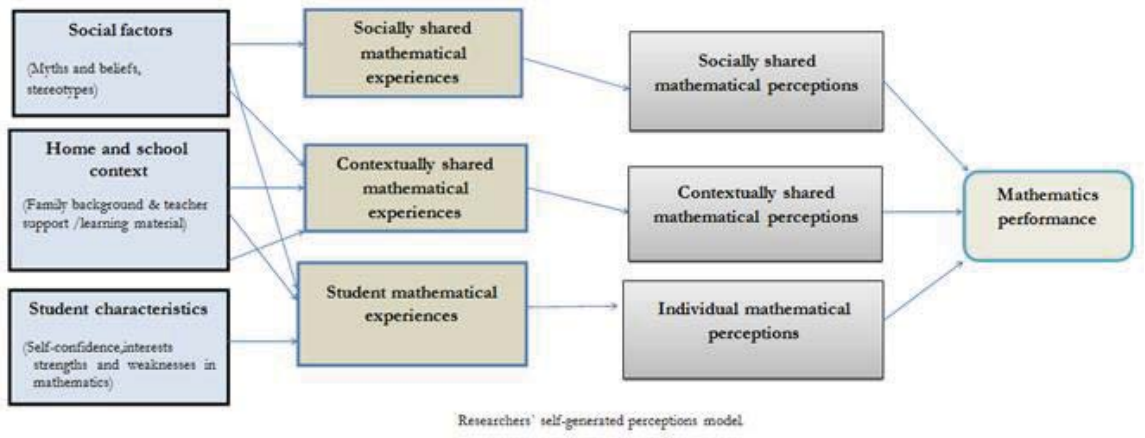

\section{Methodology}

A quantitative research approach was used. The researchers used a quantitative approach because, as noted by Kabungaidze, Mahlatsana and Ngirande (2013), quantitative research design allows the researcher to answer questions about the relationships between measured variables with the purpose of explaining, predicting and controlling certain phenomena. The study population consisted of both male and female grade 10 students from a selected high school in Limpopo province of South Africa. The total size of the population was $150(\mathrm{~N}=150)$. Using the RaoSoft sample size calculator, a minimum recommended sample size of 124 respondents was obtained. The respondents were selected using a simple random sampling method.

A 57-item self-administered questionnaire divided into seven categories of perceptions was designed using existing instruments as well as information which emerged from the literature. The questionnaire consisted of three sections, namely the Biographical and occupational data questionnaire, the perceptions section and the performance section. The biographical and occupational data questionnaire was constructed by the researchers to tap information relating to certain key biographical and occupational variables relating to the respondents such as gender, age and home. This information was used mainly for a description of the sample.

Perceptions and performance variables were identified from literature and a 5-point likert scale was designed by the researchers. Responses to each of the items were rated with anchors labelled: $1=$ strongly disagree, $2=$ disagree, 3 $=$ neither agree nor disagree, $4=$ agree, $5=$ strongly agree. The reliability was tested using the Cronbach Alpha coefficient and a coefficient of 0.910 was achieved, hence the reliability of the instrument can be accepted based on Cooper and Schindler (2008)'s argument that any coefficient above 0.70 implies reliability of the instrument. The Cronbach's alpha coefficients for the sub-categories of the identified perceptions were also calculated and the results are shown in the table 1 below.

Table 1: Reliability Statistics

\begin{tabular}{lcc}
\hline \multicolumn{1}{c}{ Description } & Cronbach's Alpha & Number of items \\
\hline Mathematics Performance & .695 & 4 \\
Strength and weaknesses in mathematics & .699 & 4 \\
Teacher /learning material support & .868 & 10 \\
Family background and support & .701 & 4 \\
Interests in mathematics & .713 & 8 \\
Difficulties or challenges in learning mathematics & .738 & 8 \\
Self confidence inmathematics & .648 & 9 \\
Myths and beliefs about mathematics & .789 & 10 \\
Overall Questionnaire reliability & .910 & 57 \\
\hline
\end{tabular}


To observe content validity, the questionnaire was adopted and structured so that the questions posed were clearly articulated and directed. All statements were formulated to eliminate the possibility of misinterpretations. This was followed by a pre-tested administered to 87 students who were excluded from the participants in the main study. The identified amendments were made to ensure the simplicity and clarity of some questions, making it fully understandable to the participants (Masitsa, 2011).

In administering the questionnaire, the following procedure was followed:

- The researchers personally requested the school principal permission to distribute the copies of the questionnaire. Questionnaire distribution was done in such a way as to cause no disturbance to student's classes.

- The researchers distributed the questionnaire to the respondents during breaks (e.g. lunch time) and also ask the respondents to deposit completed questionnaires in a locked box located in the school administration building where they will be collected after three days. A covering letter assuring the prospective respondents of anonymity and confidentiality was accompanying the questionnaire. This covering letter also informs the prospective respondent what the study was about and ask him/her to respond to the questionnaire voluntarily.

The returned questionnaires were inspected to determine their level of acceptability. They were coded. The data was transferred to an Excel sheet. A statistical computer package, Statistics Package for Social Sciences (SPSS) version 20.0, was used to process the results. Descriptive statistics (e.g. means and standard deviations) were used to describe the data in summary form. Pearson product-moment correlation coefficient was used to measure the relationships between the variables (i.e. myths and beliefs, strengths and weaknesses in mathematics, self confidence in mathematics, family background and support as well as interests in mathematics) and the dependent variable (mathematics proficiency). Standard multiple regression analysis was also carried out to assess the relative contribution of the independent variables to the variability of the dependent variable. To test the demographic mean differences, Analysis of Variance (ANOVA) and t-test were used.

\section{Results}

\subsection{Response rate}

A follow up of the questionnaires showed a good response rate from the research participants. At the end of the data collection phase, the total number of the completed questionnaires was 124. Given that the sample size of the study was 150 , this represented a response rate of $82.7 \%$. Many observers presumed that higher response rates assure more accurate survey results (Holbrook, Krosnick, \& Pfent, 2008). Response rates $(60-70 \%)$ are considered as ideal for this type of study (Babbie, 2013).

\subsection{Subjects}

The sample consisted of 124 secondary school students. Table 1 presents demographical data of the study sample.

Table 2: Demographic variables

\begin{tabular}{ccc}
\hline Variable & $\begin{array}{c}\text { Frequency } \\
\text { Gender }\end{array}$ & Percentages \\
\hline Male & 51 & 41 \\
Female & 73 & 59 \\
& Age & 63 \\
16-20 years & 78 & 37 \\
21 years and above & 46 & 72.5 \\
& Home language & 4.8 \\
\hline Sepedi & 90 & 10.5 \\
Shangane & 6 & 8.1 \\
Venda & 13 & 4.1 \\
\hline Swati & 10 & \\
Other & 5 &
\end{tabular}


Demographic data about the respondents shows that $73(59 \%)$ were females and $51(41 \%)$ were males. The majority $78(63 \%)$ of the participants were in the $16-20$ years category. Sepedi dominated the home languages $90(72.5 \%)$ while Venda $13(10.5 \%)$ was also notable. The other languages were insignificantly represented. The school is dominated Sepedi speaking students.

\subsection{Perception constructs Summary descriptive statistics}

Data collected were analysed in an effort to explore the perceptions of students regarding mathematics. In particular, the identified perceptions focused on eight (8) constructs: (i) mathematics performance, (ii) difficulties or challenges in learning mathematics, (iii) myths and beliefs about mathematics, (iv) family background and support, (v) self confidence in mathematics, (vi) teacher /learning material support, (vii) interests in mathematics, (viii) weaknesses in mathematics.

Table 3: Summary descriptive statistics

\begin{tabular}{clccc}
\hline Item & \multicolumn{1}{c}{ Description } & Mean & Std. Deviation & Rank \\
\hline $\mathbf{1}$ & Mathematics Performance & 3.5181 & 1.4993 & 1 \\
$\mathbf{2}$ & Difficulties in learning mathematics & 3.1431 & .56863 & 2 \\
$\mathbf{3}$ & Myths and Beliefs about mathematics & 3.1379 & .4657 & 3 \\
$\mathbf{4}$ & Family background and Support. & 3.1126 & .61158 & 4 \\
$\mathbf{5}$ & Self confidence in mathematics & 3.0789 & .524595 & 5 \\
$\mathbf{6}$ & Teacher /Learning material support & 3.0570 & .5755 & 6 \\
$\mathbf{7}$ & Interests mathematics & 2.9969 & .61989 & 7 \\
$\mathbf{8}$ & Weaknesses in Mathematics & 2.8347 & .74687 & 8 \\
\hline
\end{tabular}

The overall mean for each construct were analysed and are shown in table 3 above. The results showed that students perceive mathematics proficiency (overall mean $(M)=3.5181$, with a standard deviation $(S D=1.4993$ ) as the main contributing factor to their success in Mathematics. Students perceive that it is worthwhile for one to ask himself/herself: "What does he wants us to do? They also confirmed that the more the time spend studying mathematics the better the results in tests and assignments. They also revealed the contributions of effort and endurance when solving a problem, usually lead to correct results. To solve math problems accurately and efficiently, students confirmed that one needs to develop flexibility and to learn multiple strategies.

Difficulties in learning mathematics were also perceived as another form obstacle that affects some sections of students. Difficulty in learning mathematics also presents itself as a difficulty in applying formulae, using measurements, writing out phases of calculations, writing numbers, and spatial perception. Students who struggle with mathematics perceive that the amount of material in any mathematics is so overwhelming making it difficult to absorb. Students also perceive mathematics as a huddle one has to cross in order to progress to the next grade level. Students also indicated their academic progress is hampered by low scores in mathematics even if they are performing well in other subjects.

Myths and Beliefs about mathematics were also ranked highly (mean=3.1379, SD=. 4657) in terms of its contribution to students' liking and disliking of mathematics. Myths in relation to gender and maths are not the only ones that have the potential to have a negative impact on students' learning in maths. Maths is valued because it is considered by the community to be an indicator of intelligence. Students' feelings of lack of control could stem from the idea that maths is "difficult" or that you have to have a "maths brain" in order to succeed in the subject. Feelings of lack of control can be due to cultural norms, such as negative stereotypes about image and gender. Women are often too ready to admit inadequacy and say, "I just can't do math.". The idea that math ability is mostly genetic is one dark facet of a larger fallacy that intelligence is mostly genetic. The results revealed that student' beliefs about what mathematics is and what it is not has an effect on their overall performance.

Weaknesses in mathematics was least ranked (mean=2.8347 and SD $=0$.74687). Thus most students do not perceive that their weaknesses or strength in tackling mathematics problems has an effect on their performance. 
Table 4: Gender and Age mean differences

\section{One-Sample Test}

\begin{tabular}{|c|c|c|c|c|c|c|}
\hline & \multicolumn{9}{|c|}{ Test Value = 0 } \\
\cline { 6 - 7 } & \multirow{2}{*}{$\mathrm{t}$} & $\mathrm{df}$ & \multirow{2}{*}{ Sig. (2-tailed) } & \multirow{2}{*}{ Mean Difference } & \multicolumn{2}{|c|}{ 95\% Confidence Interval of the Difference } \\
\cline { 6 - 7 } & & & 1.4113 & Lower & Upper \\
\hline Gender & 31.809 & 123 & .000 & 3.3710 & 3.323 & 1.499 \\
Age & 77.393 & 123 & .000 & 3.285 & 3.457 \\
\hline
\end{tabular}

A t-test was conducted to test whether there was a significant difference between male and female students' mathematics perceptions. It must be recalled that the study hypothesised that there is a significant difference between male and female students' mathematics perceptions. The results for the test are shown in table 4 above (df $=123, \mathrm{t}=$ $31.809, p=0.00$ ). The null hypothesis was rejected since the $p$-value is less than 0.05 . Therefore we conclude that there is a significant difference in the way mathematics is perceived between males and females. This is consistent with findings by Hoang (2008) who showed that male consistently reported slightly more positive perceptions and attitudes than females. However a research carried out by Mohamed and Waheed (2011) showed that the students' positive attitude towards mathematics is medium and there is no gender difference in their attitudes.

A t-test was also conducted to test whether there was a significant difference in views and attitudes towards mathematics between the two age cohorts of students. The results for the test are shown in table 4 above (df=123, $t$ $=77.393, p=0.00$ ). The null hypothesis was rejected since the $p$-value is less than 0.05 . Therefore we conclude that there is a significant difference in views and attitudes towards mathematics between the two age cohorts of students.

To test if there are significant differences in perceptions among students from different language backgrounds, an Analysis of Variance (ANOVA) test was conducted to test the following hypothesis.

$\mathrm{H}^{0}$ : There is no significant difference in math perceptions among students from different language backgrounds.

$\mathrm{H}^{1}$ : There is a significant difference in math perceptions among students from different language backgrounds.

The results of the test in table 6 below show that ( $d f=1, d f=122, F=0.160, p=0.690)$. Therefore, we do not reject the null hypothesis since $p>0.05$ and conclude that there are no significant differences in mathematics perceptions among students from different language backgrounds.

Table 6: ANOVA (Home language and perception mean differences)

\begin{tabular}{|cc|c|c|c|c|c|}
\hline \multirow{2}{*}{ Home language } & & Sum of Squares & df & Mean Square & F & Sig. \\
& Between Groups & .427 & 1 & .427 & .160 & .690 \\
& Within Groups & 325.444 & 122 & 2.668 & & \\
& Total & 325.871 & 123 & & & \\
\hline \multirow{3}{*}{ Mathematics performance } & Between Groups & .087 & 1 & .087 & .154 & .696 \\
& Within Groups & 68.810 & 122 & .564 & & \\
& Total & 68.897 & 123 & & & \\
\hline \multirow{3}{*}{ Weaknesses in mathematics } & Between Groups & .514 & 1 & .514 & .920 & .339 \\
& Within Groups & 68.097 & 122 & .558 & & \\
\hline \multirow{3}{*}{ Teacher /learning material support } & Total & 68.611 & 123 & & & \\
& Between Groups & .148 & 1 & .148 & .443 & .507 \\
& Within Groups & 40.596 & 122 & .333 & & \\
\hline \multirow{3}{*}{ Family support } & Total & 40.743 & 123 & & & \\
\hline & Between Groups & .159 & 1 & .159 & .423 & .517 \\
& Within Groups & 45.848 & 122 & .376 & & \\
\hline \multirow{2}{*}{ Interests in mathematics } & Total & 46.007 & 123 & & & \\
& Between Groups & .288 & 1 & .288 & .749 & .388 \\
& Within Groups & 46.976 & 122 & .385 & & \\
\hline \multirow{2}{*}{ Difficulties in mathematics } & Total & 47.264 & 123 & & & \\
& Between Groups & .007 & 1 & .007 & .025 & .875 \\
& Within Groups & 32.380 & 122 & .265 & & \\
\hline \multirow{2}{*}{ Myths and beliefs } & Total & 32.387 & 123 & & & \\
& Between Groups & .098 & 1 & .098 & .448 & .504 \\
& Within Groups & 26.578 & 122 & .218 & & \\
\hline & Total & 26.676 & 123 & & & \\
\hline
\end{tabular}


Further tests on the different constructs identified showed that there are no perception differences as all the $\mathrm{p}$-values are all greater than 0.05 . This means that there are no significant differences in the ways students perceive weaknesses in mathematics, teacher support/learning material, family background and support, interests in mathematics, difficulties in doing mathematics, self-confidence and myths and beliefs about mathematics. The seven constructs seem to have the same contribution to the students' performance.

Table 7: Correlation Analysis: The strength and direction of the relationship between independent variables (myths and beliefs, weaknesses in mathematics, self confidence in mathematics, family background and support as well as interests in mathematics) and the dependent variable (mathematics performance)

\begin{tabular}{|c|c|c|c|c|c|c|c|c|c|}
\hline \multicolumn{10}{|c|}{ Correlations } \\
\hline & & $\begin{array}{c}\text { Maths } \\
\text { performance }\end{array}$ & $\begin{array}{c}\text { Weaknesses in } \\
\text { mathematics }\end{array}$ & \begin{tabular}{|c|} 
Teacher /learning \\
material support
\end{tabular} & \begin{tabular}{|l|} 
Family \\
support
\end{tabular} & $\begin{array}{l}\text { Interests in } \\
\text { mathematics }\end{array}$ & $\begin{array}{l}\text { Difficulties in } \\
\text { mathematics }\end{array}$ & \begin{tabular}{|c|} 
Self \\
confidence
\end{tabular} & $\begin{array}{c}\begin{array}{c}\text { Myths and } \\
\text { beliefs }\end{array} \\
\end{array}$ \\
\hline \multirow{3}{*}{$\begin{array}{l}\text { Mathematics } \\
\text { performance }\end{array}$} & \begin{tabular}{|c|} 
Pearson \\
Correlation
\end{tabular} & 1.000 & $.407^{* *}$ & $.756^{* *}$ & $.652^{*+}$ & $.797^{\text {t+ }}$ & $.688^{*+*}$ & $.826^{* *}$ & $.713^{* *}$ \\
\hline & $\begin{array}{l}\text { Sig. (2- } \\
\text { tailed) }\end{array}$ & . & .000 & .000 & .000 & .000 & .000 & .000 & .000 \\
\hline & $\mathrm{N}$ & 124 & 124 & 124 & 124 & 124 & 124 & 124 & 124 \\
\hline \multirow{3}{*}{$\begin{array}{l}\text { Weaknesses in } \\
\text { mathematics }\end{array}$} & \begin{tabular}{|c|} 
Pearson \\
Correlation \\
\end{tabular} & $.407^{*+*}$ & 1.000 & $.792^{* *}$ & $.607^{\text {t* }}$ & $.732^{*+}$ & $.771^{*+}$ & $.485^{* *}$ & $.541^{*+}$ \\
\hline & $\begin{array}{l}\text { Sig. (2- } \\
\text { tailed) }\end{array}$ & .000 & . & .000 & .000 & .000 & .000 & .000 & .000 \\
\hline & $\mathrm{N}$ & 124 & 124 & 124 & 124 & 124 & 124 & 124 & 124 \\
\hline \multirow{3}{*}{$\begin{array}{l}\text { Teacher /learning } \\
\text { material support }\end{array}$} & \begin{tabular}{|c|} 
Pearson \\
Correlation \\
\end{tabular} & $.756^{* *}$ & $.792^{* *}$ & 1.000 & $.794^{* *}$ & $.906^{*+}$ & $.782^{* *}$ & $.741^{* *}$ & $.725^{* *}$ \\
\hline & \begin{tabular}{|l|} 
Sig. (2- \\
tailed)
\end{tabular} & .000 & .000 & . & .000 & .000 & .000 & .000 & .000 \\
\hline & $\mathrm{N}$ & 124 & 124 & 124 & 124 & 124 & 124 & 124 & 124 \\
\hline \multirow{3}{*}{ Family support } & \begin{tabular}{|c|} 
Pearson \\
Correlation \\
\end{tabular} & $.652^{* *}$ & $.607^{*+}$ & $.794^{* *}$ & 1.000 & $.722^{*+}$ & $.589^{* *}$ & $.685^{* *}$ & $.582^{* *}$ \\
\hline & $\begin{array}{l}\text { Sig. (2- } \\
\text { tailed) }\end{array}$ & .000 & .000 & .000 & . & .000 & .000 & .000 & .000 \\
\hline & $\mathrm{N}$ & 124 & 124 & 124 & 124 & 124 & 124 & 124 & 124 \\
\hline \multirow{3}{*}{$\begin{array}{l}\text { Interests in } \\
\text { mathematics }\end{array}$} & \begin{tabular}{|c|} 
Pearson \\
Correlation
\end{tabular} & $.797^{*+}$ & $.732^{*+}$ & $.906^{* *}$ & $.722^{*+}$ & 1.000 & $.720^{* *}$ & $.713^{* *}$ & $.725^{*+}$ \\
\hline & $\begin{array}{l}\text { Sig. (2- } \\
\text { tailed) }\end{array}$ & .000 & .000 & .000 & .000 & . & .000 & .000 & .000 \\
\hline & $\mathrm{N}$ & 124 & 124 & 124 & 124 & 124 & 124 & 124 & 124 \\
\hline \multirow{3}{*}{$\begin{array}{l}\text { Difficulties in } \\
\text { mathematics }\end{array}$} & \begin{tabular}{|c|} 
Pearson \\
Correlation \\
\end{tabular} & $.688^{*+}$ & $.771^{* *}$ & $.782^{* *}$ & $.589^{* *}$ & $.720^{* *}$ & 1.000 & $.743^{* *}$ & $.776^{* *}$ \\
\hline & $\begin{array}{l}\text { Sig. (2- } \\
\text { tailed) }\end{array}$ & .000 & .000 & .000 & .000 & .000 & . & .000 & .000 \\
\hline & $\mathrm{N}$ & 124 & 124 & 124 & 124 & 124 & 124 & 124 & 124 \\
\hline \multirow{3}{*}{ Self confidence } & \begin{tabular}{|c|} 
Pearson \\
Correlation \\
\end{tabular} & $.826^{* *}$ & $.485^{* *}$ & $.741^{* *}$ & $.685^{* *}$ & $.713^{*+*}$ & $.743^{+* x}$ & 1.000 & $.590^{*+}$ \\
\hline & $\begin{array}{l}\text { Sig. (2- } \\
\text { tailed) }\end{array}$ & .000 & .000 & .000 & .000 & .000 & .000 & & .000 \\
\hline & $\mathrm{N}$ & 124 & 124 & 124 & 124 & 124 & 124 & 124 & 124 \\
\hline \multirow{3}{*}{ Myths and beliefs } & \begin{tabular}{|c|} 
Pearson \\
Correlation \\
\end{tabular} & $.713^{* *+}$ & $.541^{* *}$ & $.725^{* *}$ & $.582^{* *}$ & $.725^{* *}$ & $.776^{* *}$ & $.590^{* *}$ & 1.000 \\
\hline & $\begin{array}{l}\text { Sig. }(2- \\
\text { tailed) }\end{array}$ & .000 & .000 & .000 & .000 & .000 & .000 & .000 & . \\
\hline & $\mathrm{N}$ & 124 & 124 & 124 & 124 & 124 & 124 & 124 & 124 \\
\hline
\end{tabular}

Pearson Correlation analysis was used to determine the strength and direction of the relationships. Correlation is a technique for investigating the relationship between two quantitative variables, for example, teacher/learning support material and mathematics performance. Pearson's correlation coefficient $(r)$ is a measure of the strength of the association between the two variables. Table 3 shows that there is a weak positive relationship between weaknesses in mathematics and mathematics performance $(r=0.407, p=0.000)$. This means that the more the challenges a student encounters in mathematics, the less the performance. The results are compatible with Zacharia and Barton (2004) findings which revealed that a student's weaknesses in mathematics have a negative effect on performance.

The results of the study also yields a statistically significant positive correlations with teacher /learning material support and mathematics performance $(r=0.756, p=0.000)$. This means that the more a student gets enough support 
from his/her teacher, the more he/she is likely to become more proficient in mathematics. These findings are consistent with Hammond (2000) who indicates that measures of teacher quality and support strongly correlates with student achievement in mathematics.

Family background and support showed statistically significant positive correlations with mathematics performance $(r=0.652 ; p=0.000)$; interests in mathematics and mathematics performance $(r=0.797, p=0.000)$ meaning the more a student is interested in mathematics, the more chances of becoming proficient in the subject. In supported of these findings, Kupari \& Nissinen (2013) in their study concluded that students' mathematics achievement is positively correlated to family background and support.

Self-confidence showed statistically significant positive correlations with mathematics performance $(r=0.826$, $\mathrm{p}=0.000$ ). Chick \& Vincent (2005) found self-confidence to be positively correlated to achievement, with highly selfregulated students being more motivated to use planning, organizational, and self-monitoring strategies to achieve good performance in mathematics.

Statistically significant positive correlations were also found between difficulties in mathematics, myths and beliefs and performance $(r=0.688, p=0.000) ;(r=0.713, p=0.000)$ respectively. Kane and Mertz (2012) also revealed that myths and beliefs about mathematics have a strong influence on student performance.

It will be recalled that the purpose of this study was to investigate the relationship between student's perceptions and mathematics performance and it was hypothesized that there is a significant positive relationship between students' perceptions and mathematics performance. Since the p-values of all the relationships in table 3 are less than 0.05 , it therefore means that we reject the null hypothesis and conclude that there is a significant positive relationship between students' perceptions and mathematics performance.

Table 8: Regression Analysis

Model Summaryb

\begin{tabular}{|c|c|c|c|c|c|c|c|c|c|c|}
\hline \multirow[b]{2}{*}{ Model } & \multirow[b]{2}{*}{$\mathrm{R}$} & \multirow[b]{2}{*}{ R Square } & \multirow{2}{*}{$\begin{array}{l}\text { Adjusted R } \\
\text { Square }\end{array}$} & \multirow{2}{*}{$\begin{array}{l}\text { Std. Error of the } \\
\text { Estimate }\end{array}$} & \multicolumn{5}{|c|}{ Change Statistics } & \multirow{2}{*}{$\begin{array}{l}\text { Durbin- } \\
\text { Watson }\end{array}$} \\
\hline & & & & & $\begin{array}{l}\text { R Square } \\
\text { Change }\end{array}$ & F Change & $d f 1$ & $d f 2$ & $\begin{array}{c}\text { Sig. F } \\
\text { Change }\end{array}$ & \\
\hline 1 & $.925^{a}$ & .856 & .850 & .28957 & .856 & 140.726 & 5 & 118 & .000 & 2.073 \\
\hline
\end{tabular}

a. Predictors: (Constant), Myths and beliefs, Strengths and Weaknesses in mathematics, Self confidence in mathematics, Family background and support, Interests in mathematics.

b. Dependent Variable: Mathematics Performance

Coefficients $^{\mathrm{a}}$

\begin{tabular}{|c|c|c|c|c|c|c|c|c|}
\hline & \multirow{2}{*}{ Model } & \multicolumn{3}{|c|}{ Unstandardized Coefficients Standardized Coefficients } & \multirow{2}{*}{$t$} & \multirow{2}{*}{ Sig. } & \multicolumn{2}{|c|}{ Collinearity Statistics } \\
\hline & & B & Std. Error & Beta & & & Tolerance & VIF \\
\hline & (Constant) & -.636 & .194 & & -3.282 & .001 & & \\
\hline & $\begin{array}{l}\text { Strengths and Weaknesses in } \\
\text { mathematics }\end{array}$ & -.374 & .053 & -.374 & -7.108 & .000 & .440 & 2.271 \\
\hline 1 & Family background and support & .003 & .066 & .003 & .051 & .959 & .418 & 2.392 \\
\hline & Interests in mathematics & .709 & .089 & .587 & 7.943 & .000 & .223 & 4.492 \\
\hline & Self confidence in mathematics & .692 & .077 & .485 & 9.003 & .000 & .419 & 2.385 \\
\hline & Myths and beliefs & .303 & .082 & .188 & 3.698 & .000 & .469 & 2.130 \\
\hline
\end{tabular}

a. Dependent Variable: Mathematics Performance 
Collinearity Diagnostics ${ }^{a}$



a. Dependent Variable: Mathematics Performance

Residuals Statistics ${ }^{a}$

\begin{tabular}{|l|c|c|c|c|c|}
\hline & Minimum & Maximum & Mean & Std. Deviation & $\mathrm{N}$ \\
\hline Predicted Value & 1.6909 & 4.8030 & 3.5181 & .69260 & 124 \\
Residual & -.84335 & .95863 & .00000 & .28363 & 124 \\
Std. Predicted Value & -2.638 & 1.855 & .000 & 1.000 & 124 \\
Std. Residual & -2.912 & 3.310 & .000 & .979 & 124 \\
\hline
\end{tabular}

a. Dependent Variable: Mathematics Performance

Ordinary least squares regression (OLS) of the perception variables were used to determine the magnitude and direction of effects of these variables on performance. The intercept regression model was used in this analysis because some of the predictors have a possibility of being equal to zero so much that the intercept would have a meaningful interpretation. The results of that analysis are shown in Table 8 . The model indicates that $85.6 \% \%$ (R-Square $=0.856$ ) variation in student performance is explained by five (5) of the predictor variables, which are self-confidence, interest in mathematics, family background and support, weaknesses in mathematics, and myths and beliefs about mathematics. Teacher support, learning material and difficulties in doing mathematics were insignificant. The Durbin-Watson indicates that the assumption of independent error is tenable since for these data the figure is 2.073 and is close to 2 (Durbin \& Watson, 1951). No incidences of multi-collinearity were observed in the model since none of the variance inflation factors (VIF) are close to or greater than 5 . The analysis of variance table shows that the variables in the model have a statistically significant effect on performance outcomes ( $F=140.726$; Sig. $=0.000)$.

A regression model was built in the form of an equation where the dependent variable is equal to the weighted combination of the independent variables:

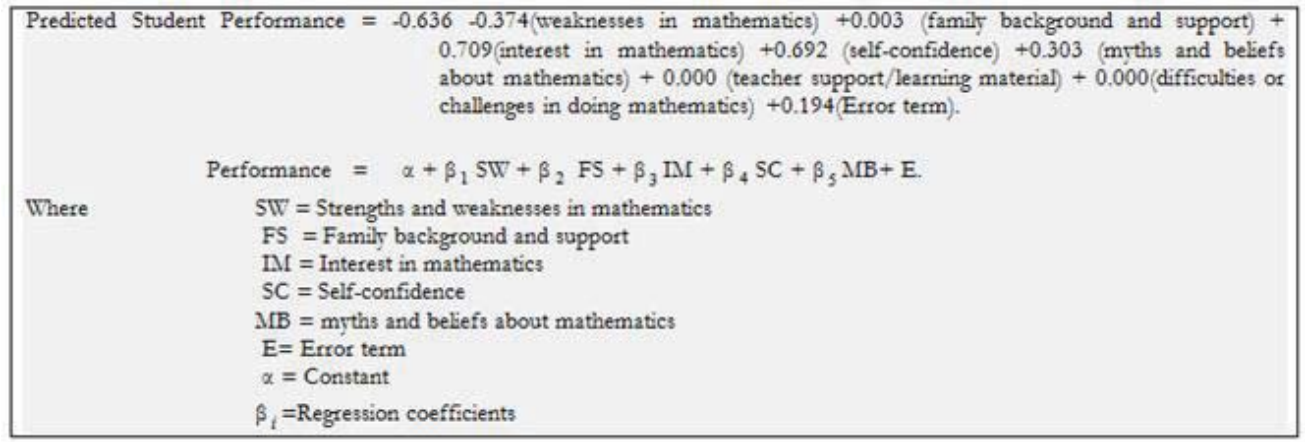

From the regression results presented in Table 8 , it can be noted that not all variables have a statistically significant effect on student performance. Statistically significant effects are observed on weaknesses in mathematics (t=-7.108, sig. 
$=0.000)$; family background and support $(\mathrm{t}=0.051$, sig. $=0.959)$; interest in mathematics $(\mathrm{t}=7.743$, Sig. $=0.000)$; selfconfidence $(t=9.003$, sig. $=0.000)$ and myths and beliefs about mathematics $(t=3.6989$, sig. $=0.000)$. Four of the five variables (family background and support (0.003), interest in mathematics $(0.587)$, self-confidence $(0.485)$, myths and beliefs about mathematics (0.188)) yield positive Beta coefficients indicating that they result in increases in student performance. Therefore, at $a=0.05$ level of significance, the study conclude that traits such as family background and support, interest in mathematics, , self-confidence and myths and beliefs about mathematics have a positive effect on students performance while strengths and weaknesses in mathematics seem to have a negative influence on students' performance. Teacher support, teaching and learning support material and difficulties or challenges in doing mathematics were considered insignificant in the regression model.

\section{Discussion of Results}

It can be recalled that the purpose of this study was to explore the students' self-perceptions on mathematics and the influence of these perceptions on achievement. The effects of demographic factors, which are gender, age and home language, were also envisaged. It was also hypothesized highly that males perceive math more positively than females.

\subsection{Gender and Perceptions}

This study found that there was a significant difference in the way mathematics is perceived between males and females. This is consistent with findings by Hoang (2008) who showed that male consistently reported slightly more positive perceptions and attitudes than females. However a research carried out by Mohamed and Waheed (2011) showed that the students' positive attitude towards mathematics is medium and there is no gender difference in their attitudes. Forgasz and Murimo (2011) also found gender differences in favour of male students' perceptions. Isiksal and Cakiroghi (2010) also claim that boys are perceived to be better at mathematics than girls. Research shows that girls have lower self-esteem than boys (Kleinfeld, 2006). Female students suffer a severe drop in self-esteem at adolescence while males gain in self-assurance as they age while girls lose the vitality and sense of self they displayed in the lower grades.

\subsection{Age and Perceptions}

This study found that there was a significant difference in views and attitudes towards mathematics between the two age cohorts of students. Descriptive statistics indicated that 16-20 year old students perceive mathematics differently than older students. This is consistent with findings by Martinot and Désert (2007) which revealed that age was not statistically significant in explaining perception levels the different age groups.

\subsection{Language and Perceptions of Mathematics}

This study found that there was a significant difference in perceptions of mathematics across different language cohorts. Analysis of variance confirmed that language factors have no effect students' perceptions of mathematics. South Africa is a multi-cultural and multi-lingual country, students from different language backgrounds tent to perceive mathematics differently. Students use language to communicate and to understand mathematics concepts. Language influences students' thought by moulding perceptions and structuring ideas Nordin (2005). This may be due to the lack of ability in understanding of the subject matter and the instructional language. Language effects and perceptions of mathematics have been extensively studied and results are inconsistent, with a number of studies revealing that the knowledge and skills are new, unfamiliar and different from the language used in everyday life (Marissa, 2009). This may cause a problem in the understanding of the mathematics concepts. Many researchers recommended that emphasis should be given more on building up students' proficiency in English before they could learn mathematics effectively.

\subsection{Relationships between perception constructs and performance}

The results emanating from the research also indicate that there is a statistically significant positive relationship between teacher and learning materials supports a, family background and support, self-confidence, myths and beliefs, difficulties in mathematics and performance in mathematics. From the above analysis one can assert that teacher/learning material support, family background and support, self-confidence, myths and beliefs as well as difficulties in mathematics can 
predict performance in mathematics. However, there was a statistically significant positive weak relationship between weaknesses in mathematics and performance among the sample of students selected to participate in the research. Since the $p$-values were less than 0.05 it therefore means that we reject the null hypothesis and conclude that the identified constructs can predict performance.

Several relationships observed in this study were similar to findings of previous researchers. For example, student beliefs were significantly related to several types of academic outcomes. Lynch (2002) found that students' selfperceptions of their reading ability were significantly associated with achievement whereas self-confidence beliefs were associated with good performance in examinations.

In general, students who attributed their academic success to factors such as self-confidence, interest in mathematics as well as family background and support tended to show higher achievement levels than students who attribute their academic outcomes to natural talent or to good luck. In support of this claim, Wentzel and Wigfield (1998) shared the same sentiments.

\section{Conclusion and Recommendations}

This study investigated the range of perception constructs towards mathematics performance shared by students at a selected South African secondary school. Results from regression analysis revealed that five of the seven factors were found to be influential on students' performance in mathematics. The influence of factors such as weaknesses in mathematics, teacher support/learning material, family background and support, interest in mathematics, difficulties in doing mathematics, self-confidence and myths and beliefs about mathematics were identified as the major causes of such perceptions. Results reveal that gender-related factors have an influence in the way students perceive mathematics. It also revealed that age has an effect on students' perceptions of mathematics. Language-related effects were also found to significantly affect students' performance.

This study has implications for all stakeholders, including teachers, schools and parents. The research reveals that's students who believe that their efforts will improve their performance are likely to enhance their achievement. Therefore this study recommends that parents and teachers should play a significant role in shaping students' perceptions and attitudes towards mathematics. It also recommends that students should not be discouraged by past experiences in lower grades that convince them that they cannot do well in mathematics.

Additionally, higher maths ability is often believed to go hand-in-hand with greater levels of general intelligence. Many students tend to subscribe to this attitude towards maths. However the study recommends that students should not hold on to such myths and beliefs about mathematical intelligence that can affect their performance. If they believe that intelligence in mathematics is a fixed quantity, something they have or do not have, but not something they acquire over time, and they may not see the point of extra effort. Finally, if students attribute their success to their innate talents rather than effort, they may not be motivated to work.

\section{References}

Aguilar, M. S., Rosas, A., \& Zavaleta, J. G. M. (2012). 12th International Congress on Mathematical Education Topic Study Group 278 July - 15 July, 2012, COEX, Seoul, Korea.

Attalla, F., Bryant, S., \& Dada, R. (2009). Learner and teacher conceptions and dispositions of mathematics from a Middle Eastern perspective. US-China Education Review, 7(7).

Babbie, E. (2013). Practice of Social Research. Belmont, California: Wadsworth Cengage Learning Cengage Learning.

Borasi, R. (1990). The invisible hand operating on mathematics instruction: Students' conceptions and expectations. Reston: NCTM.

Brown, D. (2006). Teachers' implicit theories of expression in visual arts education: A study of Western Australian teachers. Unpublished Doctoral thesis. Cowan University.

Buhagiar, D. (2013). Views of Mathematics. Jesuit in Malta, ST Aloysius College.

Chamberlin, A. S. (2010). A review of Instruments Created to Assess Affect in Mathematics. Journal of Mathematics Education, 3 (1), 167-182.

Chick, H. L., \& Vincent, J. L. (Eds.) (2005). Students' motivational beliefs, self-regulation strategies and mathematics achievement Proceedings of the 29th Conference of the International Group for the Psychology of Mathematics Education, 3, 321-328.

Crawford, K., Gordon, S., Nicholas, J., \& Prosser, M. (1993). Learning mathematics at university level: Initial conceptions of mathematics. In B. Atweh, C. Kanes, M. Carss, \& G. Booker (Eds.), Contexts in mathematics education. Proceedings of the Sixteenth Annual Conference of the Mathematical Education Research Group of Australasia Brisbane: Mathematics Education Research Group of Australasia.

De Villiers, R. (2007). Migration from developing countries: the case of South African teachers to the United Kingdom. Perspectives in 
Education, 25 (2), 67-76.

Durbin, J., \& Watson, G. S. (1951). "Testing for Serial Correlation in Least Squares Regression, II". Biometrika, 38 (1-2): $159-179$.

Ernest, P. (1995). Values, gender and images of mathematics: a philosophical perspective. International Journal of Mathematics Education, Science and Technology, 26 (3), 449-462.

Forgazs, H., \& Murimo, A. E. (2011). Depictions of females and males in Mozambican and Victorian (Australia) primary mathematics textbooks. Pythagoras, 66: 85-96.

Frank, M. L. (1990). What myths about mathematics are held and conveyed by teachers? Arithmetic Teacher, 37(5), 10-12.

Furinghetti, F. \& Pehkonen, E. (2002). Rethinking characterisations of beliefs. In G. Leder, E. Pehkonen \& G. Törner (Eds.), Beliefs: A hidden variable in mathematics education? Dordrecht: Kluwer Academic Publishers.

Gadanidis, G. (2012). Why can't I be a mathematician? FLM Publishing Association, Fredericton, New Brunswick, Canada.

Hammond, L. D. (2000). Teacher Quality and Student Achievement. Education Policy Archives, 8 (1), 1-44.

Hannula, M. S. (2007). The effect of achievement, gender and classroom contexts on upper secondary students' mathematical beliefs. Lyon France.

Hoang, T. N. (2008). The effects of grade level, gender, and ethnicity on attitude and learning environment in mathematics in high school. International Electronic Journal of Mathematics Education, 3 (1).

Holbrook, A. L., Krosnick, J. A., \& Pfent, A. (2008). The Causes and Consequences of Response Rates in Surveys by the News Media and Government Contractor Survey Research Firms. John Wiley \& Sons.

House, J. D. (2006). Mathematics Beliefs and Achievement of Elementary School Students in Japan and the United States: Results From the Third International Mathematics and Science Study. The Journal of Genetic Psychology, 167(1), 31-45.

Iddo, G., \& Ginsburg. L. (1994). The Role of Beliefs and Attitudes in Learning Statistics: Towards an Assessment Framework. Journal of Statistics Education, 2, (2).

Ignacio, N. G., Nieto, L. J. B., \& Barona, E. G. (2006). The affective domain in mathematics learning. International Electronic Journal of Mathematics Education, 1(1), 16-32.

Isiksal, M., \& Cakiroghi, E. (2010). Gender Differences Regarding Mathematics Achievement: The Case of Turkish Middle School Students. School Science and Mathematics, 108 (3), 113-120.

Kaasila, R., Hannula, M. S., Laine, A., \& Pehkonen, E. (2006). Facilitators for change of elementary teacher student's view of mathematics. International Group for the Psychology of Mathematics Education, 3(3), 385-392.

Kane, J. M., \& Mertz, J. E. (2012). Debunking Myths about Gender and Mathematics Performance. Notices of the Ams, 59, (1).

Kayander, A., \& Lovric, M. (2005). 'Transition from Secondary to Tertiary Mathematics: McMaster University experience'. International Journal of Mathematical Education in Science and Technology, 36(2-3), 149-160.

Kimball, M., \& Smith, N. (2013). The Myth of 'I'm Bad at Math'. AM ET, October 28.

Kislenko, K., Breiteig, T., \& Grevholm, B. (2005). Beliefs and attitudes in mathematicsteaching and learning. Trondheim:Nasjonalt Senter for Matematikk i Opplæringen.

Kleinfeld, J. (2006). Five powerful strategies for connecting boys to school. Pare presented at the White House Conference on Helping America's Youth. Indianapolis, Indiana.

Kupari, P., \& Nissinen, K. (2013). Background factors behind mathematics achievement in Finnish education context: London: Routledge.

Lavasania, M. G., \& Khandana, F. (2011). The effect of cooperative learning on mathematics anxiety and help seeking behaviour. Procedia Social and Behavioral Sciences, 15: 271-276.

Leder, G. C., Pehkonen, E., \& Törner, G. (2002a). Setting the scene. In G. C. Leder E. Pehkonen \& G. Törner (Eds.), Beliefs: A hidden variable in mathematics education? Dordrecht: Kluwer Academic Publishers.

Leder, G. C., Pehkonen, E., \& Törner, G. (Eds.). (2002b). Beliefs: A hidden variable in mathematics education? Dordrecht: Kluwer Academic Publishers.

Leder, G. C. \& Forgasz, H. J. (2002). Measuring Mathematical Beliefs and Their Impact on the Learning of Mathematics. Dordrecht: Kluwer Academic Publishers.

Lynch, J. (2002). Parents, self-efficacy beliefs, parents' gender, children's reader self-perceptions, reading achievement and gender. Journal of Research in Reading, 25, 54-67.

Marissa, R. (2009).Current Issues and Perspectives on Second Language Learning of Science. Studies in Science Education, 35(1).

Martinot, D. Désert, M. (2007). Awareness of a gender stereotype, personal beliefs and self-perceptions regarding math ability: when boys do not surpass girls. Soc Psychol Educ, 10:455-471.

Masitsa, M. G. (2011). Exploring safety in township secondary schools in the Free State Province. South African Journal of Education, 31:163-174.

McLeod, D. B. (1992). Research on affect in mathematics education: A conceptualisation. New York: Macmillan.

Mohamed, L., \& Waheed, H. (2011). Secondary Students' Attitude towards Mathematics in a Selected School of Maldives. International Journal of Humanities and Social Science, 1 (15).

Moscucci, M. (2008). About mathematical belief systems awareness. Working Group, 2, 298-307.

Moreau, M. P., Mendick, H. \& Epstein, D. (2010). Constructions of mathematicians in popular culture and learners' narratives: a study or mathematical and non-mathematical subjectivities. Cambridge Journal of Education, 40(1): 25-38.

Mtetwa, D., \& Garofalo, J. (1989). Beliefs about mathematics: An overlooked aspect of student difficulties. Academic Therapy, 24(5), 611-618. 
Nordin, A.B. (2005). Students' perception on teaching and learning mathematics in English. Current Issues in Language Planning, 11, (4).

Op't Eynde, P., De Corte, E., \& Verschaffel, L. (2002). Framing students' mathematics-related beliefs: A quest for conceptual clarity and a comprehensive categorization. Dordrecht: Kluwer

Osborne, R. J., Bell, B. F. dan Gilbert, J. K. (1983). Science teaching and children's views of the world. Eur. J. Sci. Educ, $5(1), 1$ - 4.

Pehkonen, E. (1997). Some results in the international comparison of pupils' mathematical views. Psychology of Mathematics Education, 1:267-274.

Pehkonen, E., \& Pietilä, A. (2003). On relationships between beliefs and knowledge in mathematics education. Paper presented at the CERME 3: Third conference of the European society for research in mathematics education, Bellaria, Italy.

Philipp, R. A. (2006). Mathematics teachers' beliefs and affect. Teachers and teaching, 7, 257-315

Picker, S. H., \& Berry, J.S. (2000). Investigating pupils' images of mathematicians. Educational Studies in Mathematics, 43 (1), $65-94$.

Rensaa, R. J. (2006). The image of a mathematician. Philosophy of Mathematics Education Journal, 19:118.

Renzi, L. (2005). The influence of teachers' beliefs on literature instruction in the high school english classroom. Unpublished dissertation, Ohio State University.

Sam, L. C. (2002). Public images of mathematics. Philosophy of Mathematics Education Journal, 15:15.

Schoenfeld, A. H. (2008). Explorations of Students' Mathematical Beliefs and Behaviour. Journal for Research in Mathematics Education, 20(4), 338-355

Sewell, B. (1981). Use of mathematics by adults in daily life. Leicester, UK: Advisory Council for Adult and Continuing Education (ACACE).

Spaull, N. (2012). Poverty \& Privilege: Primary School Inequality in South Africa. A working paper of the department of economics and the bureau for economic research at the University of Stellenbosch.

Thompson, A. G. (1992). Teachers' beliefs and conceptions: a synthesis of the research. New York: Macmillan.

Tobias, S. (2003). Overcoming math anxiety. New York: W. W. Norton \& Company.

Wentzel, K. R. \& Wigfield, A. (1998) .Academic and Social Motivational Influences on Students' Academic Performance. Educational Psychology Review, 10(2), 155-175.

Zacharia, Z., A. (2004). Urban middle-school students' attitudes toward a defined science. Science Education, 88(2): $197-222$. 